\title{
The Power of the Read Aloud in the Age of the Common Core
}

\author{
Vickie Johnston ${ }^{*}$
}

Florida Gulf Coast University, Fort Myers, FL 33965, United States

\begin{abstract}
The implementation of Common Core Standards for English Language Arts (2010) will require the use of more complex text and an increase in the use of informational text; however, reading research and best practices in literacy instruction confirm the value of a narrative read-aloud. Read-aloud time using narrative texts must still be included as a vital part of literacy instruction. Reading aloud to students increases vocabulary development, enhances fluency and oral language, introduces students to diverse population or cultural diversity, and develops critical thinking and problem solving skills. An effective read-aloud can enable students to learn about different types of conflicts and possible solutions as well as empathy and understanding for others. An effective twenty-minute read-aloud can expose students to the same academic words that would be found in content area textbooks and motivates students to become engaged in reading.
\end{abstract}

Keywords: Common Core Standards, community engagement, read-aloud.

\section{INTRODUCTION}

The Common Core State English Language Arts (ELA) Standards were created in order to develop a unitary system with learning goals outlining what students should know and be able to do at the end of each grade (CCSS, 2010). While they set expectations for student achievement across each grade level, they do not define how teachers should teach; they simply outline what students should know and be able to do. These standards were created to ensure that all students, regardless of where they live, graduate from high school with the skills and knowledge necessary to succeed in college, career, and life (CCSS, 2010). The Common Core contains a cumulative model of expectations, moving students into more complex texts earlier in their schooling in order to improve the text levels they will be able to read after graduating high school. The ELA component of the Common Core requires greater emphasis on informational text as well as an increase in text complexity. As states begin to implement these standards, it is important to remember what we have learned through literacy research. Although text complexity and informational text must become part of our curriculum, there is still great value in a narrative readaloud. Read-aloud time using narrative texts must still be included as a vital part of literacy instruction; literacy research supports this. A systematic method of reading aloud enables a teacher to scaffold a child's understanding by modeling strategies for making inferences, clarifying meaning, teaching vocabulary, enhancing fluency and oral language, and developing critical thinking and problem solving skills. It also introduces students to diverse perspectives or customs of diverse populations, teaching students to empathize and understand others.

\footnotetext{
*Address correspondence to this author at the Florida Gulf Coast University, Fort Myers, FL 33965, United States; Tel: 239-590-4329;

Fax: 239-590-7801; E-mail: vjohnston@fgcu.edu
}

\section{PREVIOUS RESEARCH}

In 1985, The Commission on Reading stated, "The single most important activity for building knowledge required for eventual success in reading is reading aloud to children" (Anderson, Hiebert, Scott, \& Wilkinson, 1985, p. 23). Research has shown that reading aloud positively influences vocabulary and syntax (Roberts, 2008; Sénéchal \& LeFevre, 2002; Whitehurst, Arnold, Epstein, \& Angell, 1994). Lane and Wright (2007) confirmed this, reporting on interventions that increase children's vocabulary, increase their ability to recognize words, and promote syntactic development during a read-aloud. Although, some researchers did not find a correlation between parent and child reading aloud and future first grade reading success (Scarborough \& Dobrich, 1994), and some even found a negative relationship between the amount of time kindergarteners spent reading aloud and their decoding skills (Meyer, Wardrop, Stahl, \& Linn, 1994), most acknowledged the benefits, across all grades levels, when a read-aloud was presented in a systematic way (Dickinson \& Tabors, 2001; Dreher, 2003; Fountas \& Pinnell, 2006; Ivey, 2003; Lapp \& Fisher, 2009). Most researchers do agree on the fact that simply reading a book out loud to students will not merit later success in oral language, vocabulary, or comprehension. Research has shown that reading-aloud can positively affect literacy development if delivered in an interactive way.

\section{METHOD OF DELIVERY}

An interactive read-aloud, as defined by Fountas and Pinnell (2006), is a systematic and explicit method of reading aloud where the teacher models vocabulary development, reading fluently, and comprehension strategies and requires the students to join in the discussion, thus becoming interactive participants in their own learning. Dickinson and Tabors (2001) found that the most effective read-aloud was an interactive read-aloud in which children were not simply passive listeners but were actively involved 
making predictions and asking and answering questions. Simply asking children questions during an interactive readaloud was found to be ineffective in vocabulary growth; however, unless students were able to engage in dialogue about the text. Growth was related to how students engaged in this dialogue or interactive talk. Lapp and Fisher (2009) confirmed this with high school students, as well, and found it to be true across all content areas.

Lane and Wright (2007) stressed the importance of a systematic approach in delivering an effective read-aloud. They found that choosing the right book and structuring how the dialogue would be delivered was key to a successful read-aloud. Teacher modeling was found to be important, as well. According to Lane and Wright (2007), research designed methods work better than naturally occurring methods. Consequently, teachers must plan the dialogue, demonstrating his or her thought process, in order to justify his or her thinking or metacognition. The most effective read-aloud must engage children in extended conversations through open-ended questions. This dialogue or interactive reading asks questions, such as "what, when, where, why", encourages children to become active learners, and then provides feedback in response to those questions. This feedback should challenge a child's understanding and raise the complexity of the conversation to a level above the child's current level (DeTemple \& Snow, 2003). This dialogue teaches a child to monitor comprehension, summarize what has happened, and clarify understanding. By presenting a read-aloud in an interactive way, teachers can also share their thinking as they attempt to make sense of the text, teaching students metacognition. This requires students to make predictions or inferences that explain a character's motivation or the author's purpose and requires them to connect events from different parts of the story. All of this is supported by Common Core ELA Standards, as they require a student to be able to make logical inferences while reading text (CCSS, 2010).

\section{VOCABULARY DEVELOPMENT}

Hargrave and Sénéchal (2000) found that an interactive read-aloud resulted in vocabulary gains even when those interactive interventions were short. They found the more students added new words through dialogue, experience, and book discussions, the more they added these new words to their vocabulary; consequently, they paid more attention to the multiple meanings of these new words (Hargrave \& Sénéchal, 2000). This dialogue or dialogic reading (Whitehurst, et al., 1994) paralleled research found with other systemic approaches to a read-aloud, such as a thinkaloud (Fisher \& Frey, 2014) text talk (Beck \& McKeown, 2001), and print referencing (Ezell \& Justice, 2000).

Beck and McKeown's (2001) text talk approach was found to help kindergarten and early elementary students expand their vocabulary. Teachers would insert short definitions to a few vocabulary words found in the readaloud. The questioning techniques were found to be similar to dialogic readings or think-alouds, as they would ask the children open-ended questions which required the children to expand on their explanations rather than responding with one or two word responses. After reading, teachers would discuss the vocabulary words in both the context of the story and in other contexts. In other words, although the teacher might plan to target several specific words from the story, he or she chose whether or not to discuss these words in more depth, depending on the student responses.

Ezell and Justice (2000) found that print referencing, a strategy that requires the teacher that is reading the book to specifically refer to the verbal and non-verbal cues, increased the metalinguistic focus of the read-aloud interactions. The metalinguistic features include the text functions, text forms, and text features. According to Ezell and Justice (2000), print-referencing cues, which can be verbal or nonverbal, refer to pointing or tracking the print, asking questions, or making comments about print when reading. All of these systemic approaches required students to justify their responses by referring back to the read-aloud itself, either by using print or pictures to justify their answers.

According to Himmele and Himmele (2012), "A 20minute effective read-aloud can repeatedly expose children to academic words that will likely show up in content textbooks" (para 5). They also stated that "narrative readalouds is an effortless way to help students acquire the academic language they will need to comprehend informational texts" (Himmele and Himmele, 2012, para 4). By transforming our read-alouds into interactive read-alouds, dialogic read-alouds, or "think alouds", we give children explicit guidance on vocabulary, pronunciation, and syntax. In all of this parallels the emphasis on increasing text complexity and developing critical thinking found in The Common Core ELA Standards. Systematic approaches to reading-aloud require teachers to scaffold children's understanding of the book being read, model strategies for learning new vocabulary and concepts, model how to draw inferences and explanations directly from the text, and increase the overall quality of children's questions and responses. Biancarosa and Snow (2006), confirmed this need in older students, recommending the use of multiple literacies, best practices, innovative strategies, and explicit strategies; and they found the need to promote engagement, critical thinking, and encouragement of metacognition in these older readers.

\section{FLUENCY AND ORAL LANGUAGE}

Successful read-alouds are delivered using expressions, voices, and gestures in order to capture the children's attention and engage them in the story. They provide the teacher with opportunities to model fluent reading and enhance students' listening and oral language, as well. Through a read-aloud, teachers can model reading strategies and demonstrate the ways in which the language of the book is different from spoken language, help students understand the patterns and structures of written language, and scaffold students learning of new words and ideas while exposing them to a variety of genres.

Oral language was found to be fostered by both immediate and nonimmediate talk. According to Dickinson and Tabors (2001), "Immediate talk focuses on answering literal questions and labeling pictures. Nonimmediate talk extends beyond the text" (p. 669). This nonimmediate oral language included discussions, word meaning discussions, predictions, text-to-self experiences, inferencing, and clarifying meaning. It included discussions of meanings, 
making predictions and inferences, and discussions of the students' experiences. In their review of literature on oral language development, Pinnell and Jaggar (2003) also reported the importance of read-alouds in the development of oral language in first and second English language learners. Reese and Cox (1999) found benefits to oral language when students were encouraged to describe illustrations, and Robbins and Ehri (1994) found benefits in discussing book events. They found that students with a higher word knowledge made greater gains by hearing unfamiliar words repeated during a read-aloud (Robbins \& Ehri, 1994). Barnes (1992) found that an effective read-aloud improved language expression throughout all curriculum subjects, and Crago and Crago (1976) found fluency benefits in reading a book repeatedly.

Common Core ELA Standards for speaking and listening require students to participate in a range of conversations and collaborations, require students to be able to express their ideas clearly and persuasively, and require students to be able to adapt their speech to a variety of contexts (CCSS, 2010). Consequently, research and best practices continue to support teacher read-alouds as a significant avenue to foster fluency and oral language across grade levels.

\section{DIVERSE PERSPECTIVES OR CUSTOMS OF DI- VERSE POPULATIONS}

In today's diverse school classrooms, students are challenged to find ways of interacting effectively with students who are culturally different; consequently, they must develop important skills in cross-cultural competence. Books chosen for read-alouds must contain engaging plots, must be well written, and must expose students to a variety of genres and diversity of characters. These should match a teacher's curriculum goals and be integrated throughout the curriculum. Many different types of text can be effective for use as a read-aloud. Banks (2003) suggested using books that portrayed accurate historical facts or perspectives in order to teach concepts of cultural similarities and differences, as well as reduce discrimination and stereotypes. Many culturally authentic children's books are about difficult subjects that might only be explained through the guidance of an adult during a read-aloud (Russell, 2009). During a read-aloud, a teacher can give a character an active voice and discuss issues such as prejudice, slavery, and discrimination.

A read-aloud may be used to deliver specific content or motivate students to explore content independently. Fisher, Flood, Lap and Frey, (2004) found that an effective readaloud increased a child's background and listening skills. Consequently, read-alouds chosen to introduce students to diverse perspectives, customs, and diverse populations can expose students to other perspectives and populations. Russell (2009) found that culturally authentic read-alouds helped minority students develop cultural pride and nonminority students develop understanding toward minority groups and reduced stereotypes previously held. The content of the read-aloud can help students to learn conflict management and encourage them to develop empathy towards other cultures that maybe different from their own experiences or culture.

Russell (2009) reported that culturally authentic children's books benefitted students when used during the early years of schooling because they encouraged tolerance in a diverse society. Roberts, Dean, and Holland (2005), discussed the importance of having a balance between readalouds that describe a group's history and those that showed the group's modern day life. Research confirms that many different types of reading materials can be appropriate to use for read-alouds; some may be used to motive and engage students to read independently, while others may be used to deliver important content. An effective read-aloud can help students learn not only about different types of conflicts and possible solutions but also acquire empathy and understanding for others.

\section{CRITICAL THINKING AND PROBLEM SOLVING SKILLS}

Research has shown that an effective read-aloud can positively influence comprehension and help to develop critical thinking and problem solving skills. Keene and Zimmerman (2007), found that effective teachers modeled their thinking as the reader as they read-aloud. They found that the successful reader was the one who unconsciously made appropriate inferences and predictions and constantly changed those predictions and rethought the current events in a story in relation to past events. Consequently, they found that effective teachers modeled what successful readers do by explicitly "thinking aloud" as they read, making students aware of how they are predicting, making an inference, or changing their ideas about what is happening in a story (Keene \& Zimmerman, 2007). Interactive read-alouds promote concept development, story schema, provide for analytic talk, incorporate teacher modeling of higher-level thinking, and require students to think critical about the text being read. Ivey (2003) confirmed this, stating that older students enjoyed read-alouds and preferred read-alouds when new information was being presented.

DeTemple and Snow (2003) reported that the dialogue between the reader and the students must teach the students to monitor their comprehension, summarize what has happened, and clarify their understanding. They concluded that this dialogue must include feedback challenging a child's understanding in order to raise the complexity of the conversation to a level above the child's current level (DeTemple \& Snow, 2003). Successful read-alouds were found to be those that planned for the specific questions to be asked during the dialogue part of a read-aloud (Whitehurst et al., 1994). This type of planning required a teacher to go deeper with their questioning in order to encourage their students to think critically, clarifying meaning and helping students to make inferences. Questions and discussions about "what, when, where, why", aided comprehension, but open-ended questions were found to allow students the ability to make inferences based on the text and expanded their critical thinking skills (Whitehurst et al., 1994).

Effective read-alouds challenged students to justify their thinking or predictions by requiring them to refer back to the text, scaffolding, and promoting metacognition (Keene \& Zimmerman, 2007). According to Ivey (2003), when teachers read aloud, they have the ability to incorporate their own background knowledge and prior experiences. By presenting a read-aloud in an interactive way, teachers can 
also share their thinking as they attempt to make sense of the text, teaching students metacognition. Teacher modeling during a read-aloud or "think aloud" can be used to teach students to make predictions or inferences that explain a character's motivation or the author's purpose and requires them to connect events from different parts of the story. According to Lane and Wright (2007), "The most positive results of reading aloud have typically been found with researcher-designed methods, as opposed to naturally occurring methods" (p. 669).

A teacher must understand the value of encouraging their listeners to use their background knowledge in order to aid in comprehending the text and must encourage his or her students' to refer back to the text in order to substantiate their predictions. Common Core ELA Standards encourage this understanding, requiring students to engage in discussions and problem solving and requiring students to refer back to the text in order to substantiate their predictions or opinions (CCSS, 2010). Effective books chosen for readalouds must be books that the reader would be able to carry on a dialogue with or aid in demonstrating one's thinking. In other words, the teacher must be a metacognitive reader or must think out loud about his or her own thinking while reading out loud. As Harvey and Goudvis (2007) stated: "Our definition of thinking aloud means that we peel back the layers of our thinking; show kids how we approach text, and make visible how understanding happens in a variety of reading contexts. To demystify the comprehension process, we share the thoughts we have as we read, surfacing our own inner conversation with the text so kids can do so independently". (p.45)

\section{CONCLUSION}

Reading aloud can increase children's vocabulary, experiential backgrounds, listening comprehension skills, syntactic development, word recognition, and their understanding about concepts of print and story (Fisher, Flood, Lap \& Frey, 2004; Lane \& Wright, 2007). Research and best practices in literacy have shown that the most effective read-alouds are those in which children are actively involved and not passively listening (Dickinson \& Tabors, 2001). Researchers have demonstrated that read-alouds are an effective way to model and motivate students to read while developing concepts of print, vocabulary, fluency, oral language, experiential backgrounds, and critical thinking skills (Fisher, Flood, Lap \& Frey, 2004; Hargrave and Sénéchal, 2000; Lane \& Wright, 2007; Whitehurst et al., 1994).

Interactive read-alouds properly delivered incorporate best practices in literacy education across grade levels. Readalouds delivered properly enable students to make predictions or inferences that explain a character's motivation; understand life from different points of view; connect events from different parts of the story; learn new vocabulary, as well as syntax, semantics, and prosody; engage in thoughtful discussions and learn metacognition; and hopefully develop a love for reading.

Although successful read-alouds typically last around twenty-minutes, research has shown that extension activities that include writing have great benefits. One of the requirements of the Common Core ELA Standards is for students to be able to write to research or to support their opinion through text. Consequently, successful read-alouds that provide activities that allow students to respond to the text that was read are beneficial. Best practices in literacy support this. According to Harvey and Goudvis (2007), "Whereas talk is most likely the most immediate way to respond to reading, writing allows readers to really work out their thinking in relation to the text" (p. 56).

In the successful classrooms today, teachers must be cognizant of their students' academic and emotional levels and seek to engage and motivate students to learn. This, in turn, instills an ownership for learning in each individual student. Interactive, dialogic read-alouds, if delivered effectively, provide an opportunity for deeper comprehension and critical thinking because students become part of the discussion. This builds on and results in knowledge, vocabulary, advanced language development, empathy for others through understanding diverse cultures and people groups, and develops higher level thinking and problem solving, all of which are supported by Common Core ELA Standards. Successful read-alouds actively engage students in literacy and teach students to use similar strategies and thought processes in order to understand complex information both in a classroom setting and the world around them.

\section{CONFLICT OF INTEREST}

The author confirms that this article content has no conflict of interest.

\section{ACKNOWLEDGEMENTS}

Declared none.

\section{REFERENCES}

Anderson, R.C., Hiebert, E.H., Scott, J.A., \& Wilkinson, I.A.G. (1985). Becoming a nation of readers: The report of the Commission on Reading. Washington, DC: National Institute of Education.

Banks, J.A. (2003). Teaching strategies for ethnic studies. New York: Allyn and Bacon.

Barnes, D. (1992). From communication to curriculum (2 $2^{\text {nd }}$ ed.). Portsmouth, NH: Boynton/Cook Heinemann.

Beck, I.L., \& McKeown, M.G. (2001). Text talk: Capturing the benefits of read-aloud experiences for young children. The Reading Teacher 55, 10-20.

Biancarosa, C., \& Snow, C. (2006). Reading next-A vision for action and research in middle and high school literacy: A report to the Carnegie Corporation of New York (2nd ed.). Washington, DC: Alliance for Excellent Education.

Common Core State Standards Initiative. (2010). Common Core State Standards for English language arts\& literacy in history/social studies, science, and technical subjects. Washington, DC: National Governors Association Center for Best Practices and the Council of Chief State School Officers. Retrieved from www.corestandards.org

Crago, H., \& Crago, M. (1976). The untrained eye? A preschool child explores Felix Hoffman's "Rapunzel." Children's Literature in Education, 22, 135-51.

DeTemple, J., \& Snow, C.E. (2003). Learning words from books. In: A. van Kleeck, S.A. Stahl, \& E.B. Bauer (Eds.), On reading books to children: Parents and teachers (pp.16-36). Mahwah, NJ: Erlbaum.

Dickinson, D.K., \& Tabors, P.O. (2001). Beginning literacy with language. Baltimore: Brookes.

Dreher, S. (2003). A novel idea: Reading aloud in a high school English classroom. English Journal, 93, 50-53. 
Ezell, H.K., \& Justice, L.M. (2000). Increasing the print focus of adult-child shared book reading through observational learning. American Journal of Speech-Language Pathology, 9, 36-47.

Fisher, D., Flood, J., Lapp, D. \& Frey, N. (2004). Interactive read-alouds: Is there a common set of implementation practices? The Reading Teacher, 58(1), 8-17.

Fisher, D., \& Frey, N. (2014). Better learning through structured teaching: A framework for the gradual release of responsibility ( $2^{\text {nd }}$ ed.). Alexandria, VA: ASCD

Fountas, I.C., \& Pinnell, S. (2006). Teaching for comprehending and fluency. Ports Mouth, NH: Heinemann.

Hargrave, A.C., \& Sénéchal, M. (2000). A book reading intervention with preschool children who have limited vocabularies: The benefits of regular and dialogic reading. Early Childhood Research Quarterly, $15,75-90$.

Harvey, S., \& Goudvis, A. (2007). Strategies that work: Teaching comprehension for understanding and engagement ( $2^{\text {nd }}$ ed.). Portland, ME: Stenhouse Publishers.

Himmele, W. \& Himmele, P. (2012). Why read-alouds matter more in the age of the common core standards. ASCD Express, 8(5) Retrieved from http://www.ascd.org/ascd-express/vol8/805-himmele.aspx

Ivey, G. (2003). The intermediate grades: "The teacher makes it more explainable" and other reasons to read aloud in the intermediate grades. The Reading Teacher, 56, 812-4.

Keene, E.O. \& Zimmermann, S. (2007). Mosaic of thought: The power of comprehension strategy instruction. Portsmouth, $\mathrm{N} \mathrm{H}$ : Heinemann.

Lane, H.B., \& Wright, T.L. (2007). Maximizing the effectiveness of reading aloud. The Reading Teacher, 60, 668-75.

Lapp, D., \& Fisher, D. (2009). It's all about the book: Motivating teens to read. Journal of Adolescent \& Adult Literacy, 52(7), 556-61.
Meyer, L.A., Stahl, S.A., Wardrop, J.L., \& Linn, R.L. (1994). The effects of reading storybooks aloud to children. Journal of Educational Research, 88, 869-84.

Pinnell, G.S., \& Jaggar, A.M. (2003). Oral language: Speaking and listening in elementary classrooms. In: J. Flood, D. Lapp, J. Squire, \& J. Jensen (Eds.), Handbook of research on teaching the English language arts ( $2^{\text {nd }}$ ed., pp. 881-913). Mahwah, NJ: Erlbaum

Reese, E., \& Cox, A. (1999). Quality of adult book reading affects children's emergent literacy. Developmental Psychology, 35, 20-8.

Robbins, C., \& Ehri, L.C. (1994). Reading storybooks to kindergartners helps them learn new vocabulary words. Journal of Educational Psychology, 86, 54-64.

Roberts, T. (2008). Home storybook reading in primary or second language preschool children: Evidence of equal effectiveness for second language vocabulary acquisition. Reading Research Quarterly, 43(2), 103-130.

Roberts, L., Dean, E., \& Holland, M. (2005). Contemporary American Indian cultures in children's picture books. Retrieved from http://www.naeyc.org/files/yc/file/200511/Roberts1105BTJ.pdf

Russel, D.L. (2009). Literature for children: A short introduction. New York: Pearson Education.

Scarborough, H. \& Dobrich, W. (1994). On the efficacy of reading to preschoolers. Developmental Review 14, 245-302.

Sénéchal, M., \& LeFevre, J.A. (2002). Parental involvement in the development of children's reading skill: A five year longitudinal study. Child Development, 73(2), 445-60.

Schmoker, M., \& Jago, C. (2013). Simplifying the ELA common core; Demystifying curriculum. Kappa Delta Pi Record, 49, 59-63.

Whitehurst, G.J., Arnold, D.S., Epstein, J.N., \& Angell, A.L. (1994). A picture book reading intervention in day care and home for children from low-income families. Developmental Psychology, 30, 679-89.

Received: August 31, 2014

Revised: November 25, 2014

Accepted: February 02, 2015

(C) Vickie Johnston; Licensee Bentham Open.

This is an open access article licensed under the terms of the Creative Commons Attribution Non-Commercial License (http://creativecommons.org/licenses/by-nc/3.0/) which permits unrestricted, non-commercial use, distribution and reproduction in any medium, provided the work is properly cited. 